\title{
Direct reprogramming of fibroblasts into diverse lineage cells by DNA demethylation followed by differentiating cultures
}

\author{
Dong-Wook Yang ${ }^{1}$, Jung-Sun Moon ${ }^{1}$, Hyun-Mi Ko' ${ }^{1}$ Yeo-Kyeong Shin ${ }^{1}$, Satoshi Fukumoto ${ }^{2}$, \\ Sun-Hun Kim ${ }^{1}$, and Min-Seok Kim ${ }^{1, *}$ \\ 'Dental Science Research Institute, School of Dentistry, Chonnam National University, Gwangju 61186, Korea, ${ }^{2}$ Division of Pediatric Dentistry, Department of \\ Oral Health and Development Sciences, Tohoku University Graduate School of Dentistry, Sendai 980-8575, Japan
}

\section{ARTICLE INFO}

Received March 31, 2020

Revised September 24, 2020

Accepted September 26, 2020

\section{*Correspondence}

Min-Seok Kim

E-mail: greatone@jnu.ac.kr

Key Words

Cell lineage

Cellular reprogramming

DNA demethylation

Epigenesis, genetic

\begin{abstract}
Direct reprogramming, also known as a trans-differentiation, is a technique to allow mature cells to be converted into other types of cells without inducing a pluripotent stage. It has been suggested as a major strategy to acquire the desired type of cells in cell-based therapies to repair damaged tissues. Studies related to switching the fate of cells through epigenetic modification have been progressing and they can bypass safety issues raised by the virus-based transfection methods. In this study, a protocol was established to directly convert fully differentiated fibroblasts into diverse mesenchymal-lineage cells, such as osteoblasts, adipocytes, chondrocytes, and ectodermal cells, including neurons, by means of DNA demethylation, immediately followed by culturing in various differentiating media. First, $24 \mathrm{~h}$ exposure of 5-azacytidine (5-aza-CN), a well-characterized DNA methyl transferase inhibitor, to NIH-3T3 murine fibroblast cells induced the expression of stem-cell markers, that is, increasing cell plasticity. Next, 5-aza-CN treated fibroblasts were cultured in osteogenic, adipogenic, chondrogenic, and neurogenic media with or without bone morphogenetic protein 2 for a designated period. Differentiation of each desired type of cell was verified by quantitative reverse transcriptase-polymerase chain reaction/western blot assays for appropriate marker expression and by various staining methods, such as alkaline phosphatase/alizarin red S/oil red O/alcian blue. These proposed procedures allowed easier acquisition of the desired cells without any transgenic modification, using direct reprogramming technology, and thus may help make it more available in the clinical fields of regenerative medicine.
\end{abstract}

\section{INTRODUCTION}

In the fields of regenerative medicine, the advent of induced pluripotent stem cells (iPSCs) has provided a great advance in overcoming the ethical difficulties of using embryonic stem cells, as well as the tissue-rejection problems in tissue replantation, by generating pluripotent cells from patients' own cells [1]. However, retroviral vectors, which are used for iPSCs derivation, are randomly integrated into the host genome, thus significantly increasing the risk of cancer by insertional mutagenesis [2-4]. Although several virus-free iPSCs induction protocols have been suggested, they are still less efficient and more technically demanding than viral transduction $[5,6]$. Considering these limitations of conventional stem cells sources, a more practical alternative approach has been required.

As an up-and-coming strategy, direct reprogramming, also known as direct conversion or trans-differentiation, has received much attention. It can be defined as converting mature somatic cells into other, distinct types of cells directly, bypassing pluripotent stem-cell intermediates [7]; it is based on the principles of

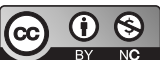

This is an Open Access article distributed under the terms of the Creative Commons Attribution Non-Commercial License, which permits unrestricted non-commercial use, distribution, and reproduction in any medium, provided the original work is properly cited. Copyright @ Korean J Physiol Pharmacol, pISSN 1226-4512, elSSN 2093-3827
Author contributions: D.W.Y. collected/analyzed/interpreted the data, and also drafted the manuscript. M.S.K. conceptualized, designed and revised the entire work. J.S.M., H.M.K., and Y.K.S. collected the data. S.H.K. and S.F. revised the manuscript critically. All authors read and approved the final manuscript. 
cell-fate specification, which can be changed by elimination of pre-existing transcriptional schemes, followed by re-establishment of a new gene regulatory network [8]. Since the first attempt at this method, in which fibroblasts were converted into myoblasts by single transfected cDNA [9], enforced insertion of specific transcription factors or pluripotency-related genes has been widely used as the major tool for cardiomyocytes, neurons, and pancreatic $\beta$ cells $[10,11]$. However, this strategy has a very narrow range of applications, because it can be used only if the master regulatory transcription factor for cell-fate specification is already known $[12,13]$. Also, it has the same safety issues that iPSCs have.

As inferred from the famous Waddington's epigenetic landscape model [14], the differentiation status and fates of cells can be shifted by epigenetic modification, which can regulate gene expressions and functions by modifying chromatin structure conformation, temporarily and reversibly, without any permanent genomic changes $[15,16]$. Among epigenetic modifications that are orchestrated by DNA methylation, histone modification, micro RNAs, and cytosine methylation have been relatively intensively studied [17]. Recently, it has been reported that differentiated cells can be converted into some somatic specialized cells, such as insulin-secreting pancreatic $\beta$ cells and functional osteoblasts, by using a reversible chemical modifier $[18,19]$, which prevents the action of the DNA methyltransferase enzyme that is mostly involved in the CpG site of DNA [20]. However, whether previous protocols suggested can be applicable more extensively to intra- or inter-lineage cell-fate conversion is not clear.

This study investigated whether fully differentiated somatic cells could be directly converted into several specialized types of cell via epigenetic modification, especially by DNA demethylation, without any permanent genetic alterations. This study proposes the possibility of applying patient-specific cell therapy to restore the damaged tissues by using easily obtainable cells, such as fibroblasts. The protocol established by this study will provide a new insight in the field of regenerative medicine.

\section{METHODS}

\section{Cell culture and chemical treatment for epigenetic modification}

NIH-3T3 fibroblast cell lines established from the primary Swiss albino mouse embryonic fibroblast cells were grown in Dulbecco's modified Eagle's medium (DMEM; Gibco BRL, Gaithersburg, MD, USA) supplemented with 10\% fetal bovine serum (FBS; Gibco BRL) and 1\% penicillin-streptomycin (Gibco BRL). When the cell confluency reached about $50 \%$, cells were treated with various concentrations of 5-aza-CN (Sigma-Aldrich Co., St. Louis, MO, USA) for $24 \mathrm{~h}$.

\section{Quantification of global DNA methylation}

Global DNA-methylation analysis was conducted using a MethylFlash Methylated DNA Quantification kit (Epigentek, Farming-dale, NY, USA), according to the manufacturer's instructions. Briefly, Genomic DNA was isolated from cells treated with 5 -aza-CN for $24 \mathrm{~h}$ by a genomic DNA isolation kit (Qiagen, Valencia, CA, USA); 100-200 ng of genomic DNA was used to quantify methylated DNA colorimetrically. The relative percentage of methylated DNA was quantified using a formula provided by the manufacturer.

\section{Cellular differentiation}

For cellular differentiation, cells were treated with or without 5-aza-CN for $24 \mathrm{~h}$, then washed with growth media and replaced in a proper differentiation medium. For osteoblastic induction, we replaced them into DMEM supplemented 2\% FBS containing $170 \mu \mathrm{M}$ ascorbic acid 2-phosphate (AA; Sigma-Aldrich), 5 $\mathrm{mM} \beta$-Glycerophosphate ( $\beta$-GP; Sigma-Aldrich) and $200 \mathrm{ng} / \mathrm{ml}$ BMP2 (R\&D Systems, Minneapolis, MN, USA). For adipogenic differentiation, the media were changed to DMEM supplemented 2\% FBS with 0.5 mM 3-isobutyl-1-methylxanthine (IBMX) (Sigma-Aldrich), $1 \mu \mathrm{M}$ dexamethasone (DEX) (Sigma-Aldrich), 100 $\mu \mathrm{M}$ Indomethacin (Sigma-Aldrich), and $10 \mu \mathrm{g} / \mathrm{ml}$ Insulin (Sigma-Aldrich). For chondrogenic differentiation, the media were changed to chondrogenic differentiation media (Gibco BRL). For neurogenic differentiation, the cells were induced by culturing in DMEM supplemented 2\% FBS, 2\% dimethyl sulfoxide (SigmaAldrich), $100 \mu \mathrm{M}$ butylated hydroxyanisole (Sigma-Aldrich). All cell differentiation media were changed every other day.

\section{Reverse transcriptase-polymerase chain reaction (RT- $P C R$ ) and real time quantitative RT-PCR (RT-qPCR)}

The total RNA was extracted using Trizol Reagent (Gibco BRL). RT was conducted with a RT system containing Moloney Murine Leukemia Virus reverse transcriptase (Promega, Madison, WI, USA). Conventional PCR was performed on a Palm Cycler thermocycler (Corbett Life Science, Sydney, Australia) and products were resolved on a 1.5\% agarose gel. Real time RT-PCR was run on a Rotor-Gene RG-3000 (Corbett Life Science) using the SYBR Green PCR Master Mix Reagent kit (Qiagen). Ratios of the intensities of the target genes and $\beta$-actin, an internal control, were used as a relative measure of the target gene expression. The mean fold change of expression in the experimental group compared with the control group was calculated using the $2^{-\Delta \Delta c t}$ method, and the range of the fold changes was calculated from the standard error of the values. To ensure experimental accuracy, real-time RTPCR assays were conducted in triplicate for each sample. Primer sequences and product sizes are defined in Table 1. 
Table 1. Oligonucleotide sequences of primers

\begin{tabular}{|c|c|c|c|}
\hline Gene & Primer sequence & Size (bp) & GenBank (accession no.) \\
\hline & Stem cell marker genes & & \\
\hline \multirow[t]{2}{*}{ SOX2 } & F 5'-TTTGTCCGAGACCGAGAAGC-3' & 146 & NM_011443.3 \\
\hline & R 5'-CTCCGGGAAGCGTGTACTTA-3' & & \\
\hline \multirow[t]{2}{*}{ KLF4 } & F 5'-GCCACCCACACTTGTGACTA-3' & 101 & NM_010637.3 \\
\hline & R 5'-TGGTAAGGTTTCTCGCCTGT-3' & & \\
\hline \multirow[t]{2}{*}{ NANOG } & F 5'-TACCTCAGCCTCCAGCAGAT-3' & 160 & NM_028016.3 \\
\hline & R 5'-CTGGTGCTGAGCCCTGAATC-3' & & \\
\hline \multirow[t]{3}{*}{ OCT4 } & F 5'-TGTGGACCTCAGGTTGGACT-3' & 189 & NM_013633.3 \\
\hline & R 5'-TTTCATGTCCTGGGACTCCTC-3' & & \\
\hline & Osteogenic marker genes & & \\
\hline \multirow[t]{2}{*}{ ALP } & F 5'-TATGGTAACGGGCCTGGCTAC-3' & 187 & NM_007431.2 \\
\hline & R 5'-TGCTCATGGACGCCGTGAAGCA-3 & & \\
\hline \multirow[t]{2}{*}{ BSP } & F 5'- GGAGGCAGAGAACTCCACAC-3' & 127 & NM_008318.3 \\
\hline & R 5'-TGCATCTCCAGССТTCTTGG-3' & & \\
\hline \multirow[t]{2}{*}{$\mathrm{OCN}$} & F 5'-TGAACAGACTCCGGCGCTAC-3' & 172 & NM_007541.2 \\
\hline & R 5'-AGGGCAGCACAGGTCCTAA-3' & & \\
\hline \multirow[t]{2}{*}{ OPN } & F 5'-GCCGAGGTGATAGCTTGGCT-3' & 177 & NM_001204201.1 \\
\hline & R 5'-TGATCAGAGGGCATGCTCAG-3' & & \\
\hline \multirow[t]{2}{*}{ RUNX2 } & 'F 5'-CCAGGCAGGTGCTTCAGAACTG-3' & 157 & NM_009820.5 \\
\hline & R 5'-ACATGCCGAGGGACATGCCTG-3' & & \\
\hline \multirow[t]{3}{*}{ OSX } & F 5'-ССТСGСТСТСТССТАTTGСАT-3' & 163 & NM_130458.3 \\
\hline & R 5'-GTTGAGGAGGTCGGAGCATA-3' & & \\
\hline & Adipogenic marker genes & & \\
\hline \multirow[t]{2}{*}{ AP2 } & F 5'-AAATCACCGCAGACGACAGG-3' & 143 & NM_024406.2 \\
\hline & R 5'-CATAACACATTCCACCACCAGC-3' & & \\
\hline \multirow[t]{2}{*}{ C/EBP } & F 5'-TTCGGGTCGCTGGATCTCTA-3' & 164 & NM_007678.3 \\
\hline & R 5'-TCA AGG AGA AACCACCACGG-3' & & \\
\hline \multirow[t]{3}{*}{ PPARG } & F 5'- ATTCTCAGTGGAGACCGCCC-3' & 165 & NM_011146.3 \\
\hline & R 5'-GACGATCTGCCTGAGGTCTG-3' & & \\
\hline & Chondrogenic marker genes & & \\
\hline \multirow[t]{2}{*}{ ACAN } & F 5'-TACGAGATCAGCTCCСTGGT-3' & 134 & NM_007424.2 \\
\hline & R 5'-TTGTAGGTGTTGGGGTCTGTG-3' & & \\
\hline \multirow[t]{2}{*}{ COL2 } & F 5'-CGAGGCAGACAGTACCTTGA-3' & 171 & NM_001113515.2 \\
\hline & R 5'-CAGTAGTCTCCGСТCTTCCAC-3' & & \\
\hline \multirow[t]{3}{*}{ SOX9 } & F 5'-GTGAAGAACGGACAAGCGGA-3' & 153 & NM_011448.4 \\
\hline & R 5'-CTGAGATTGCCCAGAGTGC-3' & & \\
\hline & Neurogenic marker genes & & \\
\hline \multirow[t]{2}{*}{ NFM } & F 5'-CGACAGCCCTCAGTCACAAT-3' & 154 & NM_008691.2 \\
\hline & R 5'-CGATGGCTGTGAGGGTTTCT-3' & & \\
\hline \multirow[t]{2}{*}{ NESTIN } & F 5'-ССССТTGССТААТАСССТTGA-3' & 114 & NM_016701.3 \\
\hline & R 5'-GCCTCAGACATAGGTGGGATG-3' & & \\
\hline \multirow[t]{2}{*}{$\beta$-actin } & F 5'-GATCTGGCACCACACCTTCT-3' & 138 & NM_007393.3 \\
\hline & R 5'-GGGGTGTTGAAGGTCTCAAA-3' & & \\
\hline
\end{tabular}

SOX2, sex determining region Y(SRY)-box 2; KLF4, Krüppel-like factor 4; OCT4, octamer-binding transcription factor 4; ALP, alkaline phosphatase; BSP, bone sialoprotein; OCN, osteocalcin; OPN, osteopontin; RUNX2, Runt-related transcription factor 2; OSX, osterix; AP2, adipocyte protein 2; C/EBP, CCAAT-enhancer-binding proteins; PPARG, peroxisome proliferator-activated receptor gamma; ACAN, aggrecan; COL2, type II collagen; SOX9, SRY-box 9; NFM, neurofilament medium.

\section{Western blot analysis}

Proteins were extracted with a lysis buffer (Cell Signaling Technology, Danvers, MA, USA) and quantified using the bicinchonic acid protein (BCA) protein-assay reagent (Bio-Rad Laboratories, Hercules, CA, USA). Proteins were resolved by $8 \%$ sodium do- decyl sulfate polyacrylamide gel electrophoresis (SDS-PAGE) and transferred to a polyvinylidene fluoride (PVDF) membrane (Whatman GmbH, Dassel, Germany). After blocking in Trisbuffered saline with $5 \%$ milk and $0.1 \%$ Tween-20, the membrane was incubated with the neurofilament medium (NFM) antibody (Biolegend, San Diego, CA, USA) or Nestin antibody (Abcam, 
Beverly, MA, USA). The mouse monoclonal primary antibody to $\beta$-actin (Sigma-Aldrich) was used as the reference. Signals were visualized using an enhanced chemiluminescence reagent (ECL; Santa Cruz Biotechnology, Santa Cruz, CA, USA) in Image Reader LAS-4000 software (Fujifilm, Tokyo, Japan).

\section{Flow cytometry analysis}

Cells were split by $0.2 \%$ ethylenediaminetetraacetic acid (EDTA) in PBS. For intracellular markers, cells were fixed and permeabilized with $90 \%$ ice-cold methanol for $30 \mathrm{~min}$ and treated with Fc block (anti-FcgRII/III) to prevent nonspecific binding for $15 \mathrm{~min}$. Indirect staining was done with primary and secondary antibodies on each step. Stained cells were analyzed on FACScan (BD Biosciences, Mountain View, CA, USA). FACS data was quantified by mean fluorescence intensity (MFI). The arithmetic mean was used in the computation of the MFI. The following antibodies and their corresponding isotype controls were used; Antibody against cluster of differentiation 146 (CD146) and octamer-binding transcription factor 4 (OCT4) was purchase from Santa Cruz Biotechnology and antibodies against mouse IgG1 and IgG2b for $\kappa$ Isotype control from Biolegend.

\section{Immunofluorescence staining}

After 14 days of neuronal differentiation, cells were fixed with $10 \%$ neutral formalin for $24 \mathrm{~h}$ and immunofluorescence staining was done using the tyramide signal amplification (TSA) Kit (Invitrogen, Carlsbad, CA, USA). Briefly, after blocking endogenous peroxidase, cells were reacted with the NFM antibody (Biolegend) overnight and subsequently with the horseradish peroxidase (HRP)-conjugated secondary antibody (Cell Signaling Technology). Cells were incubated in Alexa Fluor 488 tyramide solution (Thermo Fisher Scientific, Waltham, MA, USA) and then counterstained with propidium iodide (Thermo Fisher Scientific). Cells were photographed using an LSM confocal microscope (Carl Zeiss, Oberkochen, Germany).

\section{Cell staining}

For alkaline phosphatase (ALP) enzyme staining, cells were fixed with $4 \%$ formaldehyde, rinsed three times with deionized water, and treated with a 5-bromo-4-chloro-3-indolyl-phosphate (BCIP)/nitro blue tetrazolium (NBT) solution (Sigma-Aldrich) for $15 \mathrm{~min}$. The reaction was stopped by the addition of water, and the stains were photographed and quantified by Scion Image software (Scion Corporation, Frederick, MD, USA). To evaluate mineralization, Alizarin Red S staining was applied. Briefly, cells were fixed with $70 \%$ ethanol and then stained with $40 \mathrm{mM}$ Alizarin Red S (pH 4.2) (Sigma-Aldrich) solution for $10 \mathrm{~min}$. After extraction with $10 \%$ cetylpyridinium chloride (Sigma-Aldrich), the stain was quantified by measuring the absorbance at $570 \mathrm{~nm}$.
Oil Red O staining is performed to evaluate adipogenic differentiation. Cells were fixed with $10 \%$ formalin for $30 \mathrm{~min}$ and washed with PBS, then were stained with $0.5 \%$ Oil Red O solution (Sigma-Aldrich) for $30 \mathrm{~min}$, washed with deionized water, and photographed. The images of stained cells were acquired using an inverted contrast-phase microscope (Olympus Corporation, Tokyo, Japan).

To evaluate chondrogenic differentiation, Alcian blue staining was used. Briefly, cells were fixed with $4 \%$ formaldehyde, washed with deionized water, and stained with a $1 \%$ Alcian blue ( $\mathrm{pH} 2.5)$ (Sigma-Aldrich) solution for $30 \mathrm{~min}$. Stained cells were washed with deionized water and photographed.

\section{Statistical analysis}

Data are expressed as means \pm standard errors. Statistical analysis was carried out using the analysis of variance (ANOVA) software (Analyse-it Software Ltd., Leeds, WY, UK). Results were considered significant at a probability level of $\mathrm{p}<0.05$. For all experiments, at least three independent trials were performed.

\section{RESULTS}

\section{Transient DNA demethylation by 5 -aza-CN induced epigenetic modification in NIH-3T3 fibroblasts}

Epigenetic changes in DNA methylation affects the differentiation potential of cells. To induce epigenetic modification in NIH3T3 fibroblasts, we used 5-aza-CN, a DNA methyltransferase inhibitor, which is well known to cause DNA demethylation. First of all, in order to evaluate the capacity of 5-aza-CN to transform cell phenotypes, morphological changes of NIH-3T3 fibroblasts were examined under an inverted microscope. Exposure to $5 \mu \mathrm{M}$ 5-aza-CN for $24 \mathrm{~h}$ led standard elongated fibroblasts to display shortening and shrinking phenotypes, which were restored efficiently to their initial shape by an additional $24 \mathrm{~h}$ culture in fresh medium without 5-aza-CN (Fig. 1A). Next, we examined the effect of 5-aza-CN on DNA demethylation of NIH-3T3 fibroblasts, which were treated at the indicated concentrations of 5-aza-CN for $24 \mathrm{~h}$ and then global DNA methylation status were assessed. As shown in Fig. 1B, methylated DNA was significantly decreased in a dose-dependent manner. Finally, we assessed the multilineage differentiation potential of 5-aza-CN-treated NIH-3T3 fibroblasts by evaluating the relative gene expression levels of the stem cell markers, such as (sex determining region Y[SRY]-box 2) (SOX2), Krüppel-like factor 4 (KLF4), NANOG, and OCT4, which are transcription factors that is essential maintaining in self-renewal, or pluripotency, of undifferentiated embryonic stem cells [21]. Expression of these markers was increased clearly, and the expression changes of CD146, a mesenchymal stem cell marker [22] and OCT4 protein in 5-aza-CN-treated NIH-3T3 
A

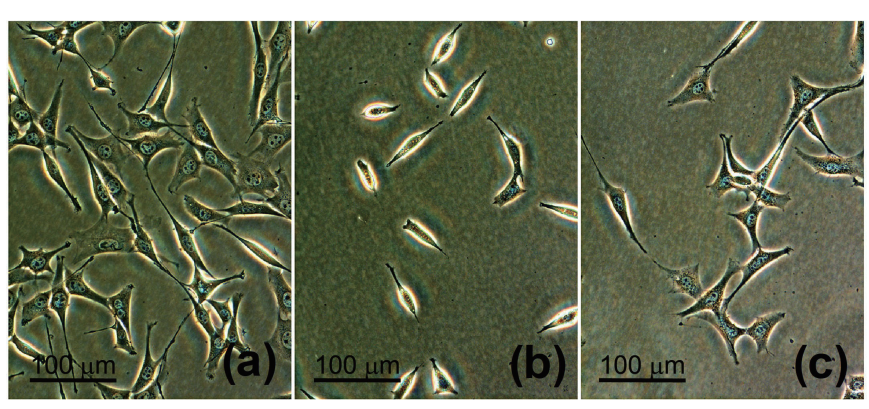

B

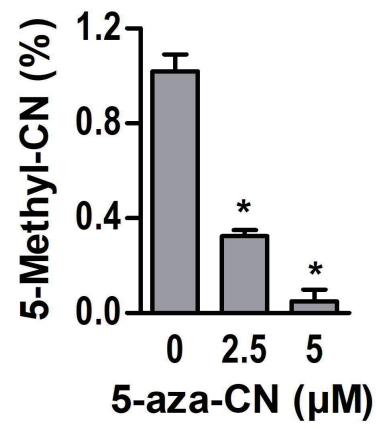

C

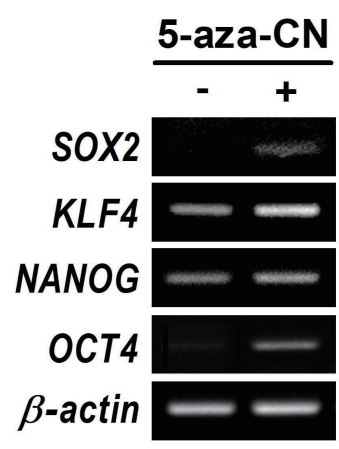

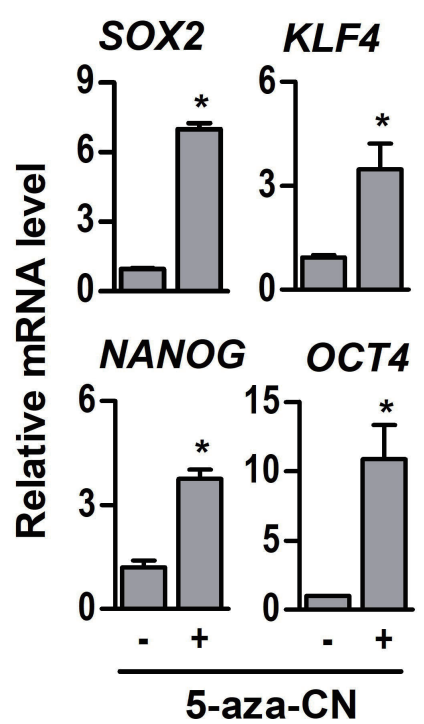

D
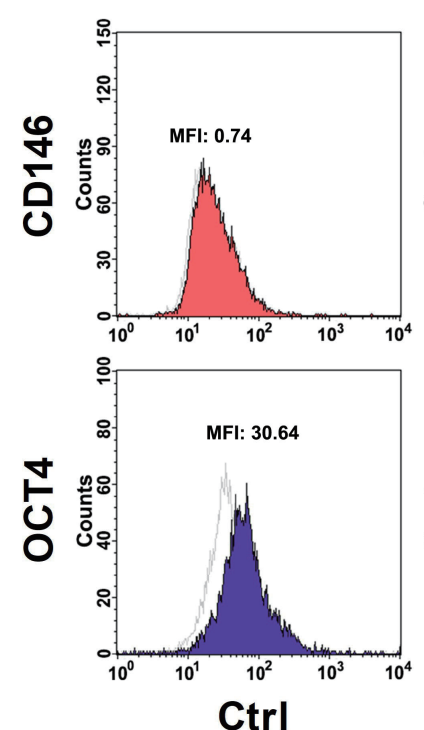
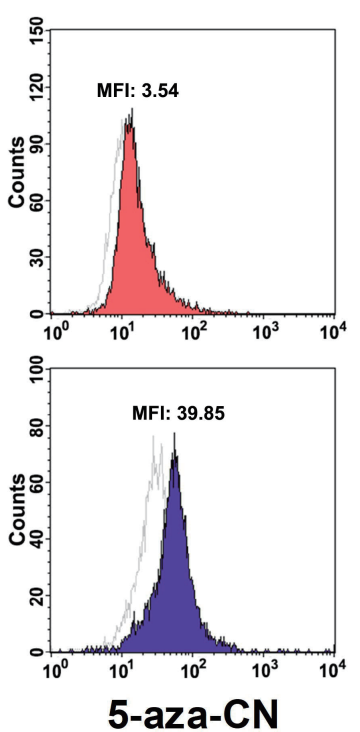

Fig. 1. Epigenetic modification in 5-azacytidine (5-aza-CN)-treated NIH-3T3 cells. (A) After 24 h of $5 \mu$ M 5-aza-CN treatment, morphologic changes of cells were observed under an inverted microscope. (a) Untreated; (b) 5-aza-CN-treated; (c) incubated in fresh media without 5-aza-CN for an additional $24 \mathrm{~h}$ after treatment with 5-aza-CN. (B) After treatment at the indicated concentrations of 5-aza-CN for $24 \mathrm{~h}$, the global DNA methylation patterns determined by using a methylated DNA quantification kit. (C) The expression of pluripotent stem cell markers such as SOX2, KLF4, NANOG and OCT4 genes was examined by conventional (left) and quantitative RT-PCR (RT-qPCR, right) with or without $5 \mu \mathrm{M} 5$-aza-CN for $24 \mathrm{~h}$. (D) The protein expression of CD146, mesenchymal stem cell marker and OCT4 was analyzed by flow cytometry with or without $5 \mu \mathrm{M} 5$-aza-CN for $24 \mathrm{~h}$, and quantified to a mean fluorescent intensity (MFI) value. Control (Ctrl) means untreated. These data represent three independent experiments. The values shown represent means \pm standard errors. SOX2, sex determining region Y(SRY)-box 2; KLF4, Krüppel-like factor 4; OCT4, octamer-binding transcription factor 4 . ${ }^{*} p<0.05$.

fibroblasts were also observed in flow cytometry analysis (Fig. 1C and D). MFI of CD146 has increased significantly from 0.74 to 3.54 , while the value of OCT4 has slightly changed.

\section{Transient DNA demethylation by 5 -aza-CN allowed the conversion of NIH-3T3 fibroblasts into mesenchymal lineage cells}

In order to evaluate the differentiation potential, brief exposure of NIH-3T3 fibroblasts to 5-aza-CN was followed by the procedure illustrated in Fig. 2A. For conversion into mesenchymal lineage cells, 5-aza-CN-treated NIH-3T3 fibroblasts were incubated with specific defined differentiation media containing $200 \mathrm{ng} /$ ml BMP2. As shown in Fig. 2B, BMP2 markedly increased the mRNA of osteogenic key molecules, such as ALP, osteopontin $(\mathrm{OPN})$, osteocalcin $(\mathrm{OCN})$, bone sialoprotein (BSP) which are major non-collagenous proteins in bone matrix, and Runt-related transcription factor 2 (RUNX2) and osterix (OSX), which are essential transcription factors for osteoblast differentiation [23], in 5-aza-CN-treated NIH-3T3 fibroblasts cultured with osteogenic medium. Furthermore, the density of ALP and AR-S staining performed to investigate early osteogenic differentiation and mineral nodule formation, respectively, were increased significantly in the group treated with both 5-aza-CN and BMP2 (Fig. 2C and D). Next, the 5-aza-CN-treated NIH-3T3 fibroblasts expressed effectively adipogenic marker genes, such as adipocyte protein 
A

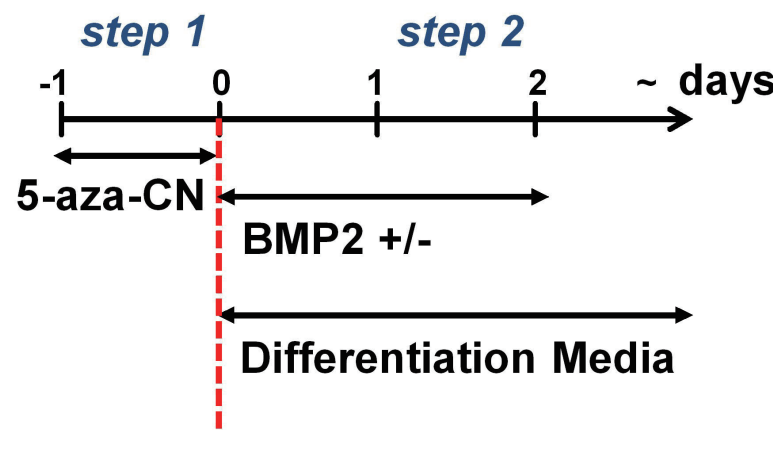

C

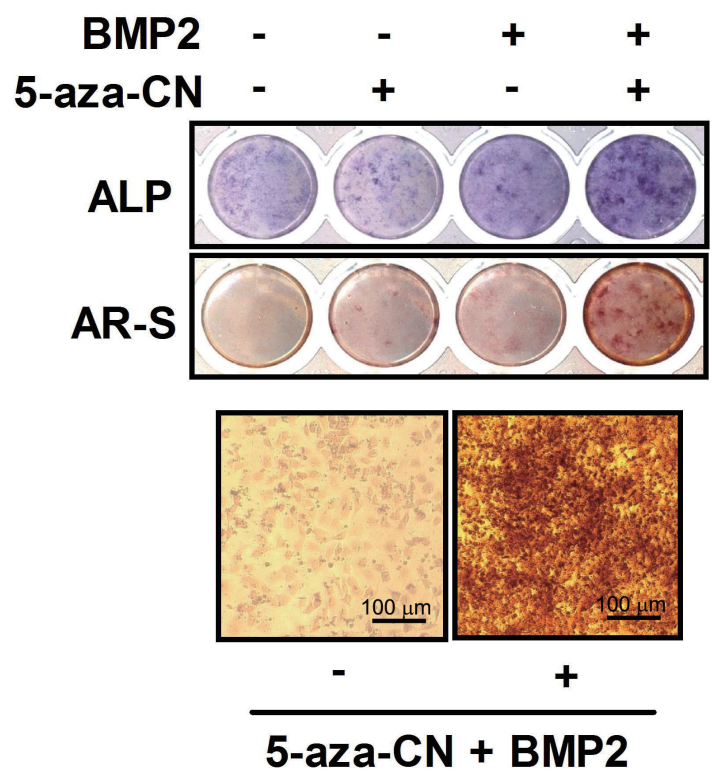

B

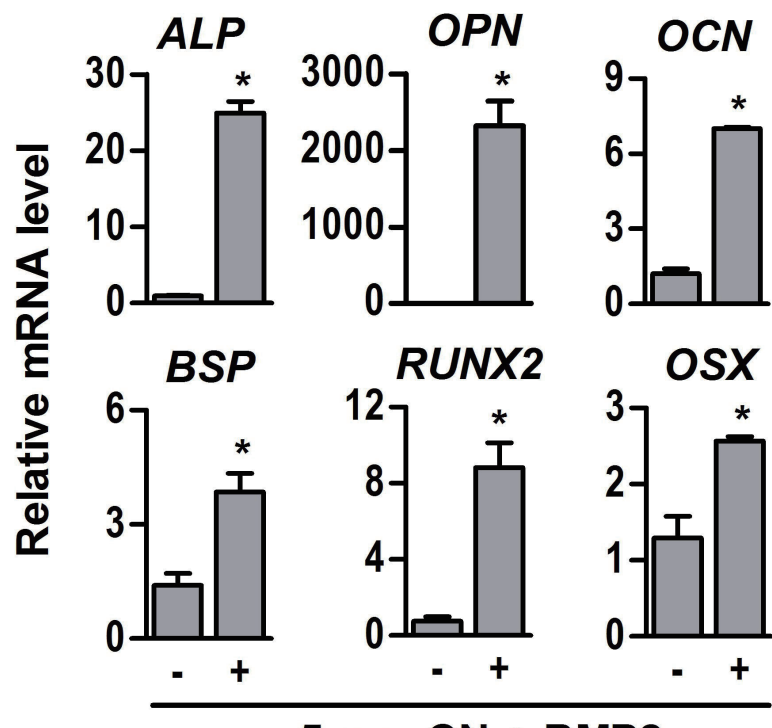

5-aza-CN + BMP2

Fig. 2. Osteogenic differentiation of 5-azacytidine (5-aza-CN)-treated NIH-3T3 cells. (A) The schematic diagram of this study is based on direct reprogramming principles. After 7 days culture in osteogenic differentiation medium (DMEM supplemented 2\% FBS containing $170 \mu \mathrm{M} \mathrm{AA}, 5 \mathrm{mM}$ $\beta$-GP and $200 \mathrm{ng} / \mathrm{ml} \mathrm{BMP2),} \mathrm{expression} \mathrm{of} \mathrm{osteogenic} \mathrm{marker} \mathrm{genes} \mathrm{such} \mathrm{as} \mathrm{alkaline} \mathrm{phosphatase} \mathrm{(ALP),} \mathrm{osteopontin} \mathrm{(OPN),} \mathrm{osteocalcin} \mathrm{(OCN),} \mathrm{bone}$ sialoprotein (BSP), Runt-related transcription factor 2 (RUNX2) and osterix (OSX) in $5 \mu \mathrm{M}$ 5-aza-CN-treated NIH-3T3 cells was determined by RT-qPCR (B), and osteogenic differentiation of 5-aza-CN-treated NIH-3T3 was verified by ALP and alizarin red S (AR-S) staining on days 7 and 14 , respectively (C). High magnification images of AR-S staining are shown in the lower panel. (D) Densities of ALP stain were quantified by Scion Image software. AR-S stain was extracted with $10 \%$ cetylpyridinium chloride and quantified by measuring the absorbance at $570 \mathrm{~nm}$ using an ELISA reader. These data represent three independent experiments. The values shown represent means \pm standard errors. ${ }^{*} p<0.05$.

2 (AP2) which is a carrier protein for fatty acid, and CCAATenhancer-binding proteins (C/EBP) and peroxisome proliferatoractivated receptor gamma (PPARG) which are key transcription factors for adipocyte differentiation [24], and vigorously formed oil droplets in a specific adipogenic medium containing BMP2 compared to control (Fig. 3A and B). Finally, in chondrogenic media, BMP2 induced chondrogenic differentiation of 5-aza-CNtreated NIH-3T3 fibroblasts, which significantly increased the expression of chondrogenic markers such as aggrecan (ACAN) and type II collagen (COL2) which are major matrix proteins of cartilaginous tissue, and SRY-box 9 (SOX9) which is essential transcription factor for differentiation of precursors cells into chondrocyte [25], as well as proteoglycan stained by Alcian blue was significantly increased (Fig. 3C and D). These results indicate that 5-aza-CN-treated NIH-3T3 fibroblasts can be converted to desired mesenchymal lineage cells capable of specific matrix formation if it is properly induced. 
A

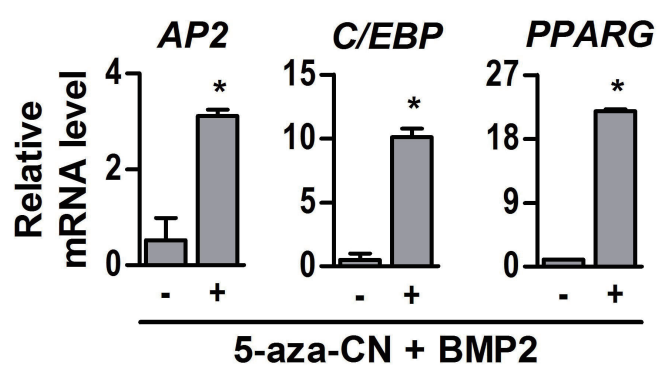

C

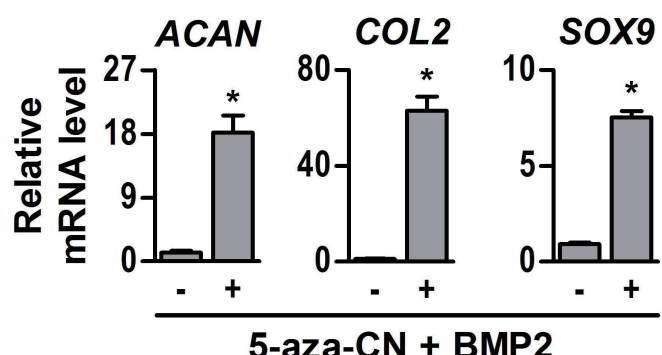

B

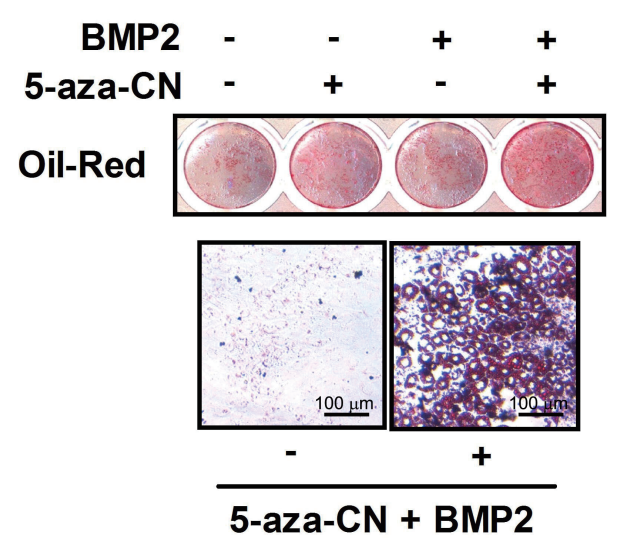

D

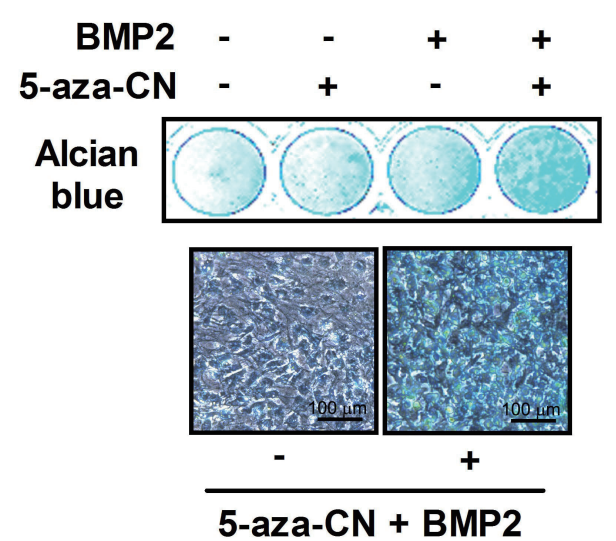

Fig. 3. Adipogenic and chondrogenic differentiation of 5-azacytidine (5-aza-CN)-treated NIH-3T3 cells. (A) After 7 days culture in adipogenic differentiation medium containing DMEM supplemented 2\% FBS with $0.5 \mathrm{mM} \mathrm{IBMX}, 1 \mu \mathrm{M}$ DEX, $100 \mu \mathrm{M}, 10 \mu \mathrm{g} / \mathrm{ml}$ insulin and 200 ng/ml BMP2, expression of adipogenic marker genes such as adipocyte protein 2 (AP2), CCAAT-enhancer-binding proteins (C/EBP), peroxisome proliferator-activated receptor gamma (PPARG) in $5 \mu \mathrm{M}$ 5-aza-CN-treated NIH-3T3 cells was quantified by RT-qPCR. (B) The lipid droplet formations were observed by OilRed $\mathrm{O}$ staining on day 14 and high magnification images of Oil-Red $\mathrm{O}$ staining are shown in the lower panel. (C) After 7 days of chondrogenic differentiation medium culture, expression of chondrogenic marker genes such as aggrecan (ACAN), type II collagen (COL2), SRY-box 9 (SOX9) in $5 \mu$ M 5-azaCN-treated NIH-3T3 cells was quantified by RT-qPCR. (D) The chondrogenic matrix formation was observed by Alcian blue staining on day 14 and high magnification images of Alcian blue staining are shown in the lower panel. These data represent three independent experiments. The values shown represent means \pm standard errors. ${ }^{*} \mathrm{p}<0.05$.

\section{Transient DNA demethylation by 5 -aza-CN allowed the conversion of NIH-3T3 fibroblasts into neuronal cells}

After epigenetic modification, NIH-3T3 fibroblasts were incubated with a defined neurogenic medium to evaluate the neurogenic potential. As shown in Fig. 4A and B, mRNA and protein of Nestin and NFM which are intermediate filament proteins expressed in nerve cells [26], were clearly increased in 5-aza$\mathrm{CN}$-treated NIH-3T3 fibroblasts. Fig. 4C shows the morphologic changes of neurogenic differentiated NIH-3T3 fibroblasts, which have an expanded cytoplasm and elongated axon-like pod as well as an increase of NFM protein in the cell cytoplasm. In contrast, control cells showed no morphological changes or NFM protein.

\section{DISCUSSION}

The observation that genetically identical cells can exhibit diverse phenotypes raises the possibility there is a novel mechanism that can modulate expressions of cell-type determinant genes. Epigenetic modification has been considered to be a promising mechanism to perform this function without genetic alteration $[15,16]$. Based on much evidence that epigenetic modification can affect cell-fate determination by changing gene transcription through a conformational change of chromatin, it has been used 
A

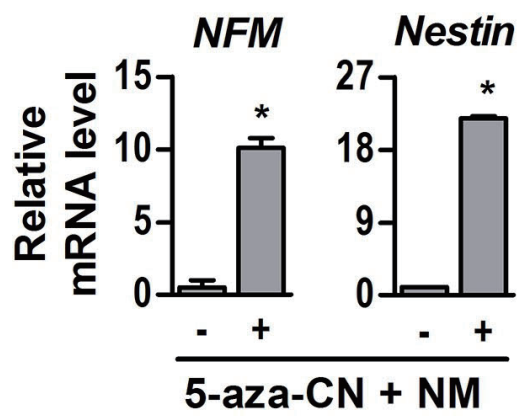

C

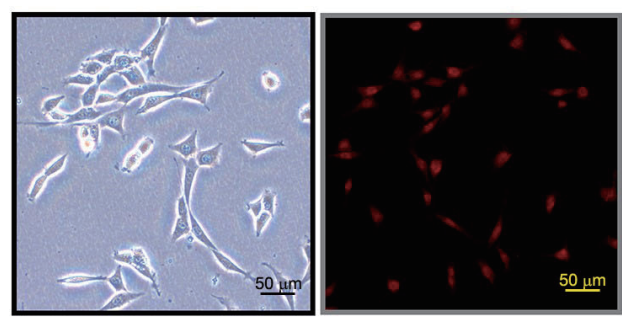

Ctrl
B

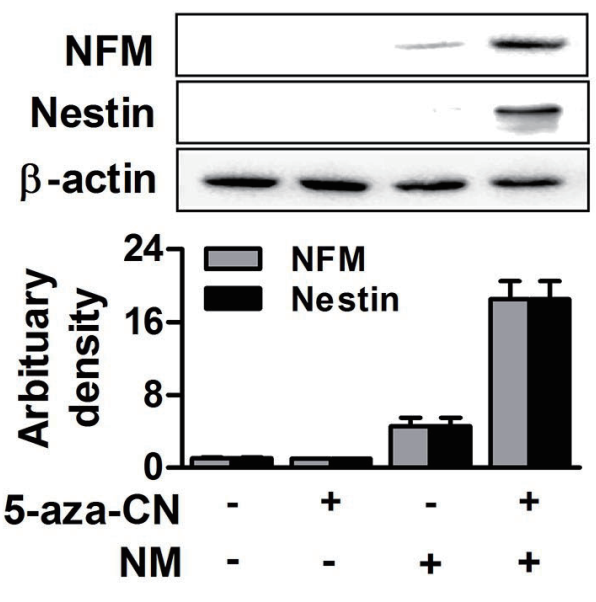

D

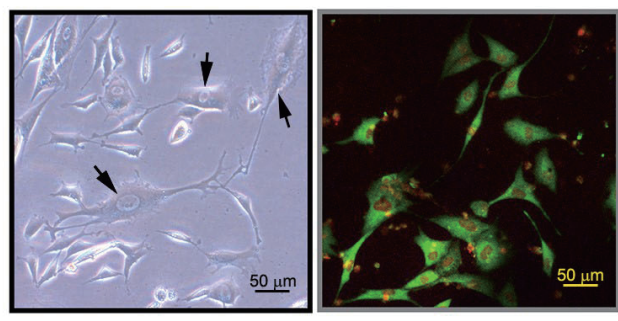

5-aza-CN + NM

Fig. 4. Neurogenic differentiation of 5-azacytidine (5-aza-CN)-treated NIH-3T3 cells. (A, B) After 5 and 14 days culture in neurogenic differentiation medium (NM) containing DMEM supplemented 2\% FBS, $2 \%$ dimethyl sulfoxide and $100 \mu \mathrm{M}$ butylated hydroxyanisole, expressions of neuronal specific intermediated filament genes such as neurofilament medium (NFM) and Nestin in $5 \mu$ M 5-aza-CN-treated NIH-3T3 cells were quantified by RTqPCR and Western blot analysis, respectively. Arbitrary densities of proteins were quantified by Scion Image software, as shown in the graph below. (C) After 14 days of neurogenic differentiation medium culture, morphologic changes in $5 \mu \mathrm{M}$ 5-aza-CN-treated NIH-3T3 cells were observed under an inverted microscope (arrows), and NFM protein expression was visualized by immunofluorescence staining. Ctrl means untreated. These data represent three independent experiments. The values shown represent means \pm standard errors. ${ }^{*} p<0.05$.

as a useful strategy to achieve lineage specification and cellular reprogramming [8].

Along with histone modification, DNA methylation, that repress the transcription, is a well-marked example of epigenetic modification extensively researched in recent years [17]. A chemical analog of cytidine, 5-aza-CN temporarily inhibits the function of DNA methyltransferase, that maintain the methylation pattern of the parent cell by recognizing hemi-methylated DNA, to form arbitrary demethylated sites in DNA, which cause changes of the cell's genetic imprinting map and ultimately activates repressed genes in heterochromated DNA [27,28]. Inspired from distinctive observations that spontaneous differentiation of mesenchymal cell lines and changes of cell phenotype appeared after exposure of 5-aza-CN [29], Pennarossa and his colleagues developed the protocol that adult fibroblasts could be transformed into endodermal pancreatic cells by brief demethylation using these chemicals [18]. Recently, it was also reported that nonosteogenic cells could be trans-differentiated into osteoblasts by epigenetic modifications followed by a specific induction step [19]. Our results revealed that if reversal of differentiation status by a temporary exposure of 5-aza-CN to mature fibroblast is immediately applied induction step for several desired cell-type-specific differentiation conditions, fibroblasts can be directly converted into diverse mesenchymal-lineage cells, such as osteogenic, chondrogenic, and adipogenic cells first. This two-step protocol enables inter-lineage conversion of fibroblast into ectodermal neuronal cells. So, if an effect of 5-aza-CN that can increase cell plasticity and coax more inducible states, assumed by expression changes of several pluripotency-related genes such as SOX2, OCT3/4, and NANOG, sequentially combined appropriate cell type determinant induction, it would be possible to allow intraand/or inter-lineage conversions of differentiated mesenchymallineage fibroblasts into all three germline originated cells.

An achievement of neuronal cell fate and identity by direct lineage reprogramming was a research subject of most attention in the field of regenerative medicine in company with cardiomyo- 
cyte due to clinical significance $[11,30]$. A majority of studies to produce functional neurons have been undertaken by transcription factor-mediated cellular reprogramming along the lines of iPSC production [30]. Although some epigenetic-based neuronal conversion approaches using chemical compound targeting chromatin-remodelling proteins have been studied, they used mostly histone modifier as adjuvants to accelerate conversion efficiency by overexpression of PAX6 and BF1 transcription factors [31] or as only constituents of chemical cocktail including BMP and TGF- $\beta$ signalling inhibitor [32]. So, suggested protocol using demethylating agent in this study may be used as a simple alternative strategy to earn functional neuronal cells.

While this study raised a possible acquisition of desired multilineage cell populations from mature fibroblasts by direct lineage reprogramming, it is also true that there are obvious limitations because functional data are insufficient to assess the quality of the differentiated cells and to whether the converted cells can work in the expected direction. Nevertheless, with further functional studies about converted cells, if suggested protocol can be finetuned by efforts to eliminate cellular toxicity of 5 -aza-CN drug and discover a precise signaling molecule to determine induced cellular fate, that substitutes for BMP-2, its efficiency to earn desired patient-specific cells from easily acquired cell source may significantly improve. It will be expected to expand its availabilities such as application in conversions into hardly-obtaining cells due to loss in the developmental process such as enamel-secreting ameloblast in the fields of regenerative medicine.

\section{ACKNOWLEDGEMENTS}

This work was supported by the National Research Foundation of Korea (NRF) grant funded by the Korea government (NRF-2018R1A2B6006373) and National Research Foundation of Korea (NRF) grant funded by the Korea government (MSIT) (No.2019R1A5A2027521).

\section{CONFLICTS OF INTEREST}

The authors declare no conflicts of interest.

\section{REFERENCES}

1. Takahashi K, Yamanaka S. Induction of pluripotent stem cells from mouse embryonic and adult fibroblast cultures by defined factors. Cell. 2006;126:663-676.

2. Schröder AR, Shinn P, Chen H, Berry C, Ecker JR, Bushman F. HIV-1 integration in the human genome favors active genes and local hotspots. Cell. 2002;110:521-529.

3. Wu X, Li Y, Crise B, Burgess SM. Transcription start regions in the human genome are favored targets for MLV integration. Science. 2003;300:1749-1751.

4. Bushman F, Lewinski M, Ciuffi A, Barr S, Leipzig J, Hannenhalli S, Hoffmann C. Genome-wide analysis of retroviral DNA integration. Nat Rev Microbiol. 2005;3:848-858.

5. Okita K, Nakagawa M, Hyenjong H, Ichisaka T, Yamanaka S. Generation of mouse induced pluripotent stem cells without viral vectors. Science. 2008;322:949-953.

6. Cohen DE, Melton D. Turning straw into gold: directing cell fate for regenerative medicine. Nat Rev Genet. 2011;12:243-252.

7. Graf T, Enver T. Forcing cells to change lineages. Nature. 2009;462: 587-594.

8. Guo C, Morris SA. Engineering cell identity: establishing new gene regulatory and chromatin landscapes. Curr Opin Genet Dev. 2017;46:50-57.

9. Davis RL, Weintraub H, Lassar AB. Expression of a single transfected cDNA converts fibroblasts to myoblasts. Cell. 1987;51:987-1000.

10. Maza I, Caspi I, Zviran A, Chomsky E, Rais Y, Viukov S, Geula S, Buenrostro JD, Weinberger L, Krupalnik V, Hanna S, Zerbib M, Dutton JR, Greenleaf WJ, Massarwa R, Novershtern N, Hanna JH. Transient acquisition of pluripotency during somatic cell transdifferentiation with iPSC reprogramming factors. Nat Biotechnol. 2015;33:769-774.

11. Xu J, Du Y, Deng H. Direct lineage reprogramming: strategies, mechanisms, and applications. Cell Stem Cell. 2015;16:119-134.

12. Song K, Nam YJ, Luo X, Qi X, Tan W, Huang GN, Acharya A, Smith CL, Tallquist MD, Neilson EG, Hill JA, Bassel-Duby R, Olson EN. Heart repair by reprogramming non-myocytes with cardiac transcription factors. Nature. 2012;485:599-604.

13. Chanda S, Ang CE, Davila J, Pak C, Mall M, Lee QY, Ahlenius H, Jung SW, Südhof TC, Wernig M. Generation of induced neuronal cells by the single reprogramming factor ASCL1. Stem Cell Reports. 2014;3:282-296.

14. Waddington $\mathrm{CH}$. The strategy of the genes: a discussion of some aspects of theoretical biology. With an appendix by H. Kacser. London: George Allen \& Unwin; 1957.

15. Goldberg AD, Allis CD, Bernstein E. Epigenetics: a landscape takes shape. Cell. 2007;128:635-638.

16. Avgustinova A, Benitah SA. Epigenetic control of adult stem cell function. Nat Rev Mol Cell Biol. 2016;17:643-658.

17. Baubec T, Colombo DF, Wirbelauer C, Schmidt J, Burger L, Krebs AR, Akalin A, Schübeler D. Genomic profiling of DNA methyltransferases reveals a role for DNMT3B in genic methylation. Nature. 2015;520:243-247.

18. Pennarossa G, Maffei S, Campagnol M, Tarantini L, Gandolfi F, Brevini TA. Brief demethylation step allows the conversion of adult human skin fibroblasts into insulin-secreting cells. Proc Natl Acad Sci U S A. 2013;110:8948-8953.

19. Cho YD, Yoon WJ, Kim WJ, Woo KM, Baek JH, Lee G, Ku Y, van Wijnen AJ, Ryoo HM. Epigenetic modifications and canonical wingless/int-1 class (WNT) signaling enable trans-differentiation of nonosteogenic cells into osteoblasts. J Biol Chem. 2014;289:2012020128.

20. Stresemann C, Lyko F. Modes of action of the DNA methyltransferase inhibitors azacytidine and decitabine. Int J Cancer. 2008;123:813.

21. Heng JC, Orlov YL, Ng HH. Transcription factors for the modula- 
tion of pluripotency and reprogramming. Cold Spring Harb Symp Quant Biol. 2010;75:237-244.

22. Hua J, Gong J, Meng H, Xu B, Yao L, Qian M, He Z, Zou S, Zhou $\mathrm{B}$, Song Z. Comparison of different methods for the isolation of mesenchymal stem cells from umbilical cord matrix: proliferation and multilineage differentiation as compared to mesenchymal stem cells from umbilical cord blood and bone marrow. Cell Biol Int. 2014;38:198-210.

23. An J, Yang H, Zhang Q, Liu C, Zhao J, Zhang L, Chen B. Natural products for treatment of osteoporosis: the effects and mechanisms on promoting osteoblast-mediated bone formation. Life Sci. 2016;147:46-58.

24. MacDougald OA, Lane MD. Transcriptional regulation of gene expression during adipocyte differentiation. Annu Rev Biochem. 1995;64:345-373.

25. Kurakazu I, Akasaki Y, Hayashida M, Tsushima H, Goto N, Sueishi T, Toya M, Kuwahara M, Okazaki K, Duffy T, Lotz MK, Nakashima Y. FOXO1 transcription factor regulates chondrogenic differentiation through transforming growth factor $\beta 1$ signaling. J Biol Chem. 2019;294:17555-17569.

26. Li D, Zou XY, El-Ayachi I, Romero LO, Yu Z, Iglesias-Linares A, Cordero-Morales JF, Huang GT. Human dental pulp stem cells and gingival mesenchymal stem cells display action potential capac- ity in vitro after neuronogenic differentiation. Stem Cell Rev Rep. 2019;15:67-81.

27. Whitelaw E, Sutherland H, Kearns M, Morgan H, Weaving L, Garrick D. Epigenetic effects on transgene expression. Methods $\mathrm{Mol}$ Biol. 2001;158:351-368.

28. Spada F, Haemmer A, Kuch D, Rothbauer U, Schermelleh L, Kremmer E, Carell T, Längst G, Leonhardt H. DNMT1 but not its interaction with the replication machinery is required for maintenance of DNA methylation in human cells. J Cell Biol. 2007;176:565-571.

29. Darmon M, Nicolas JF, Lamblin D. 5-Azacytidine is able to induce the conversion of teratocarcinoma-derived mesenchymal cells into epithelia cells. EMBO J. 1984;3:961-967.

30. Riemens RJM, van den Hove DLA, Esteller M, Delgado-Morales R. Directing neuronal cell fate in vitro: achievements and challenges. Prog Neurobiol. 2018;168:42-68.

31. Raciti M, Granzotto M, Duc MD, Fimiani C, Cellot G, Cherubini E, Mallamaci A. Reprogramming fibroblasts to neural-precursor-like cells by structured overexpression of pallial patterning genes. Mol Cell Neurosci. 2013;57:42-53.

32. Cheng L, Hu W, Qiu B, Zhao J, Yu Y, Guan W, Wang M, Yang W, Pei G. Generation of neural progenitor cells by chemical cocktails and hypoxia. Cell Res. 2015;25:645-646. 